\title{
A LEI 13.874 E OS IMPACTOS NA PARTE ESPECIAL DO CÓDIGO CIVIL OBSERVADAS AS NORMAS DO LIVRO II: DO DIREITO DE EMPRESA
}

\section{LAW 13,874 AND THE IMPACTS ON THE SPECIAL PART OF THE CIVIL CODE, IN COMPLIANCE WITH THE RULES OF BOOK II: CORPORATE LAW}

\author{
Ester Moraes D'Avila* \\ Kamilla Ranny Macedo Niz ${ }^{* * *}$
}

\begin{abstract}
Resumo
A Lei 13.874 representa uma modificação quanto aos direitos de Empresa assim como notórias mudanças no Código Civil. Deste modo, é importante analisar os impactos da sua promulgação no Direito Empresarial, tendo como enfoque a alteração no artigo 1.052, que introduz em seu parágrafo primeiro e segundo, a sociedade unipessoal, assim como a inclusão do parágrafo $7^{\circ}$ no artigo 980 -A, que versa sobre a despersonalização da Pessoa Jurídica na EIRELE. Para isso, vale observar o contexto da criação da lei, pela medida provisória 881/19 justificando levantamento de urgência no tocante a liberdade econômica, assim como as alterações concernentes as relações empresariais.
\end{abstract}

Palavras-chave: Sociedade Unipessoal, Despersonalização da Pessoa Jurídica, Medida Provisória, Liberdade Econômica, relevância ou urgência.

\begin{abstract}
Law 13,874 represents a modification of Company rights as well as noticeable changes in the Civil Code. Therefore, it is important to analyze the impacts of its promulgation on Corporate Law, focusing on the amendment to Article 1.052, which introduces in its first and second paragraph, sole proprietorship, as well as the inclusion of paragraph 7 in Article 980-A, which deals with the depersonalization of the Legal Entity at EIRELE. For this, it is worth observing the context of the creation of the law, by provisional measure 881/19 justifying an urgent survey regarding economic freedom, as well as changes concerning business relations.
\end{abstract}

Keywords: Unipersonal Society, Depersonalization of Legal Entities, Provisional Measure, Economic Freedom, relevance or urgency.

Artigo submetido em 29 de Novembro de 2019 e aprovado em 16 de Dezembro de 2019.

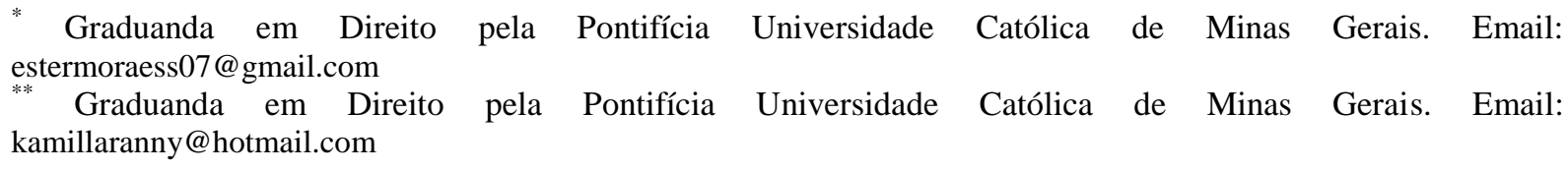




\section{INTRODUÇÃO}

No dia 20 de setembro de 2019, após intensos debates no âmbito do Congresso Nacional, foi sancionada a lei 13.874/19, denominada como "Lei da Liberdade Econômica". Essa lei originou-se da medida provisória 881/19 que foi adotada pelo Presidente da República em 30 de abril de 2019, justificando-se na urgente necessidade de afastar a percepção de que, no Brasil, o exercício de atividades econômicas depende de prévia permissão do Estado. Dessa forma, cabe analisar como originou essa lei e seus eventua is impactos no Direito empresarial.

Pautando-se na liberdade econômica, o caráter neoliberalista se materializa com a sua publicação, que foi atribuido diversas alterações nas regras que vigoram o Direito de Empresa, sendo as mais notórias mudanças, no artigo 1.052, que dispõe sobre a Sociedade Limitada, e a inclusão do $\$ 7$ no artigo 980-A, que versa sobre a desconsideração da pessoa jurídica da EIRELI.

Observados os desdobramentos da lei, é evidente que a finalidade legal, é aprimorar e sustentar a vontade contratual das partes, com mínima intervenção do Estado. Observa o professor Eduardo Tomasevicius Filho, professor de Direito da USP.

\footnotetext{
É verdade que, no Brasil, o Poder Judiciário tem amplos poderes para modificar o conteúdo contratual, o que pode gerar insegurança jurídica nos negócios, ao contrário de outros países, em que não há esse mesmo poder. Há duas razões que justificam esse fato em nosso país: o histórico de inflação, que exigia o reequilíbrio das prestações para preservação do padrão e reserva de valor da moeda; e, infelizmente, a cultura do desprezo ao Direito vigente, pela reiteração de práticas abusivas e cláusulas nulas de pleno direito, inclusive aquelas incompatíveis com a boa-fé.
}

Dessa forma, pode se afirmar que a insegurança jurídica advinda da permissão do poder judiciário de modificar o conteúdo contratual é de grande impacto. No entanto, tal medida ocorre devido os grandes abusos que o liberalismo no contrato entre as partes proporcionou, sendo necessário a intervenção do Estado para a proteção da parte hipossuficiente do contrato, em conformidade ao princípio da boa-fé.

Ao observar a liberdade Econômica num aspecto contextual, a possibilidade do mercado econômico de se 'autogerir' desencadearam crises financeiras no mundo ao longo das décadas, em exemplo a Crise de 1929 e a Crise de 2008, desencadeadas a princípio nos Estados Unidos e se disseminando pelos outros países, inclusive no Brasil. Tais crises se destacam na História frente a experiência liberalista no cenário mundial e suas respectivas consequências. 
Com a aprovação da medida provisória, o caráter liberalista se manifesta com a Lei da liberdade Econômica ao restringir a intervenção do Estado nas relações empresariais tendo como justificativa a desburocratização do ambiente de negócios nacional e a promoção das "garantias de livre mercado". Nesse aspecto, alterou-se normas e leis específicas que afetam diretamente o direito societário e as relações empresariais, ao criar a figura da Sociedade Unipessoal e a inclusão da despersonalização da pessoa jurídica na EIRELI.

Ao analisar a mudança jurídica que o legislador adiciona a Sociedade Limitada, ao incluir a possibilidade de uma Sociedade Unipessoal, é introduzido o termo "sociedade" associada a uma empresa constituída por uma única pessoa. De acordo o professor César Fiuza (2013) “As sociedades são grupos de pessoas que, com interesse de lucro, se reúnem para a realização de empreendimento qualquer. São, assim, pessoas colegiadas.”. Deste modo, observa-se claramente uma primeira contradição com o termo Sociedade Unipessoal introduzido pela medida provisória 881/19 e recepcionada pela lei 13.874/19.

A respeito do termo sociedade que faz referência a um colegiado de pessoas e o empresário individual, tal assunto também fora pauta de discussão na proposta de criação da Empresa Individual de Sociedade Limitada (EIRELI) introduzida pela Lei 12.441/11, que surgiu com o objetivo de separar o patrimônio particular do empresário individual com o da Empresa. De acordo o professor César Fiuza, "O espírito da Lei não foi o de criar um modelo de sociedade (unipessoal); foi tão somente o de possibilitar ao empresário individual (pessoa física) limitar sua responsabilidade no exercício da empresa”. Dessa forma, caberia a distinção clara da Sociedade Unipessoal da EIRELE. Ademais, discute-se a diferença entre ambas em matéria e na prática jurídica.

Outro aspecto de grande relevância é a introdução do parágrafo $7^{\circ}$ ao artigo 980 - A do Código Civil que versa sobre a despersonalização da pessoa jurídica na EIRELI. Nota-se uma clara divergência com o artigo $50^{1}$ do referido código ao limitar a responsabilidade civil dos titulares apenas em casos de fraude.

Assim, observadas tais alterações, o presente artigo tem por objetivo aprofundar sobre os impactos da aprovação da medida provisória 881 , que se oficializou com a lei 13.874 , nos artigos 1.052 e 980-A do Código Civil, assim como analisar as fundamentações apresentadas

\footnotetext{
${ }^{1} \mathrm{O}$ art. 50 do Código Civil atesta que "Em caso de abuso da personalidade jurídica, caracterizado pelo desvio de finalidade ou pela confusão patrimonial, pode o juiz, a requerimento da parte, ou do Ministério Publico quando lhe couber intervir no processo, desconsiderá-la para que os efeitos de certas e determinadas relações de obrigações sejam estendidos aos bens particulares de administradores ou de sócios da pessoa jurídica beneficiados direta ou indiretamente pelo abuso".
} 
para a necessidade de tais inclusões.

\section{A MEDIDA PROVISÓRIA}

A lei 13.874 originou-se da medida provisória $881 / 19$ que foi editada exclusivamente pelo Presidente da República e posteriormente submetida ao Congresso Nacional, ficando sujeita a conversão em lei ordinária. O artigo 62 da Constituição Federal, em seu caput, indica os pressupostos de edição da medida provisória, sendo estes: a relevância para o poder público e a urgência, que quando ausentes, levam a inconstitucionalidade que deve ser aferida pela Câmara dos Deputados e o Senado Federal.

Segundo a Comissão Mista destinada a emitir parecer sobre a Medida Provisória 881, a relevância presente na mesma esta aferida no aumento da liberdade para a iniciativa particular conceber novos empreendimentos, o que possibilitaria na geração de empregos, tributos e renda. A Comissão acrescenta também em relação à urgência, a retomada do processo de desenvolvimento econômico, sustentando o argumento na crise econômica que sustenta o país há anos.

Analisando a urgência como um dos requisitos para edição de medida provisória, o artigo $64, \S 4^{\circ}$, da Constituição Federal versa que: "Os prazos do $\S 2^{\circ}$ não ocorrem nos períodos de recesso do Congresso Nacional nem se aplicam aos projetos de código" ou seja, exclui a possibilidade de solicitação do Presidente da República em projetos de cód igo, isso porque, são normas que refletem diretamente na vida do povo, não podendo ser alvos de resultados de políticas públicas que não buscam matérias que não observem diretamente a Constituição Federal. Afirma Rogério Tadeu Romano:

\footnotetext{
Não será o Poder Executivo, por medida provisória, quem dirá, em tão pouco tempo, o que os Códigos brasileiros já versam a matéria em absoluta consonância com a Constituição. Colocou-se, pois, o presidente da República acima da cidadania e das casas legislativas ao editar, de forma apressada, tão grave documento normativo. (ROMANO,2019)
}

Aprofundando esta análise, a Medida Provisória 881 afronta o princípio da separação de poderes, positivado na Constituição Federal de 1988 no artigo $2^{\circ}$ ao salientar que: "São poderes da União, independentes e harmônicos entre si, o Legislativo, o Executivo e o Judiciário", inspirada no princípio da separação dos poderes contida na Declaração do Homem e na Constituição Francesa de 1971, que dizia "Toda sociedade que não assegura a garantia dos direitos nem a separação dos poderes não possui constituição". Ainda reforçando sua inconstitucionalidade a Medida Provisória 881 indica aos Judiciários parâmetros em que se 
devem pautar para interpretar o direito civil, matéria que é destinada ao Congresso Nacional, atribuindo nova redação ao artigo 423 do Código Civil e acrescentando os artigos 480-A e 480-B. Assim, conclui Rogério Tadeu Romano (2019): “A MP 881 não vem, como deveria vir, discutindo matéria atinente a normas especiais, mas tem a arrogância de pautar condutas que estão em normas gerais".

Desta forma, entende-se que a promulgação da medida provisória 881, também fere a

Constituição Federal de 1988 que abriga o Estado Social no Brasil, editada sem a análise dos impactos no plano fático, e sem qualquer diálogo com a sociedade.

\section{A LIBERDADE ECONÔMICA}

A dignidade da pessoa humana é um dos fundamentos do Estado Democrático de Direito em que se constitui a República brasileira, reforçando tal ideia no artigo $3^{\circ}$ da Constituição Federal. De maneira geral, o Estado deve garantir o desenvolvimento nacional, por meio de uma sociedade livre, justa e solidária. Sendo assim o principal objetivo do Estado Social é corrigir as desigualdades sociais e econômicas advindas do capitalismo. O Estado Social pretende garantir as liberdades individuais e, ao mesmo tempo, intervir para que a população tenha acesso aos serviços sociais, como educação, saúde e habitação.

Norberto Bobbio em sua obra "Liberalismo e Democracia” faz uma análise dos limites das funções do Estado. O liberalismo econômico representado pelo Estado mínimo, ou seja, mínima intervenção do Estado na esfera econômica, formaliza o Estado protetor dos direitos e não um Estado provedor dos mesmos. "[...] liberdade e igualdade são valores antitéticos, no sentido de que não se pode realizar plenamente um sem limitar fortemente o outro" (BOBBIO, 1988, p. 17 e 18).

Bobbio ainda afirma que o liberalismo e a democracia estão destinados a não se encontrar, devido há contraposição histórica entre eles. A constituição de 1988 trata da livre iniciativa como um dos fundamentos ou uma das premissas do modelo de economia no mercado regulado, mantido e estruturado pelo poder constituinte. No que se trata da formulação do texto da medida provisória 881, a livre iniciativa foi tratada como um princípio jurídico-constitucional fundamental, porém o que se deve analisar é que a previsão de um princípio jurídico fundamental na constituição em relação a este tema se encontra no artigo $1^{\circ}$ da Constituição, inciso IV "os valores sociais do trabalho e da livre iniciativa". Se a livre iniciativa realmente é entendida como princípio jurídico fundamental, todas as demais formais de regular a atividade econômica do Estado até hoje, deveriam ser tidas como inconstitucionais. 
Essa precisa distinção entre o que é fundamento ou diretriz e o princípio fundamental encontra-se no voto condutor da ADI 319-4, proferido pelo relator ministro Moreira Alves, cujo julgamento ocorreu em 03/03/1993. Decidiu-se pela constitucionalidade da Lei 8.039/1990, que dispunha sobre critérios de reajuste de mensalidades escolares. Do acórdão, publicado no DJ de 30/04/1993, extrai-se o seguinte enunciado:

Em face da atual Constituição, para conciliar o fundamento da livre iniciativa e do princípio da livre concorrência com os da defesa do consumidor e da redução das desigualdades sociais, em conformidade com os ditames da justiça social, pode o Estado, por via legislativa, regular a política de preços de bens e serviços, abusivo que é o poder econômico que visa a ao aumento arbitrário dos lucros.

Rogério Tadeu Romano (2019) então afirma que "O voto condutor do relator esclarece a distinção, ao dizer que, ao contrário da Constituição anterior, a Constituição atual passou a ter a livre- iniciativa", como um dos dois fundamentos dessa mesma ordem econômica", dando "maior ênfase à sua limitação em favor da justiça social", instituindo como princípio fundamental "não a livre- iniciativa da economia liberal clássica, mas os valores sociais da livre-iniciativa".

Para o Professor Paulo Lôbo:

\begin{abstract}
“Os artigos do Código Civil alterados pela MP 881/2019, nesse longo período, foram objeto de estudos doutrinários e de laboriosa aplicação pelos tribunais, s em jamais terem sido obstáculos à liberdade econômica ou ao e xe rcício da ativ idade econômica. Ao contrário do que subjaz a inspiração da MP 881, as normas originárias do Código Civil estão em conformidade com os princípios jurídicos fundamentais da atividade econômica estabelecidos no artigo 170 da Constituição Federal e do modelo de Estado Social, por esta adotado e inaugurado no Brasil desde a Constituição de 1934”. (LÔBO,2019)
\end{abstract}

Nota-se então, a inobservância do caput do artigo 170 da Constituição Federa 1, este que determina em seu texto "A ordem econômica, fundada na valorização do trabalho humano e na livre iniciativa, tem, por fim, assegurar a toda existência dignam conforme os ditames da justiça social, observados os seguintes princípios: " A livre iniciativa aparece enunciada como um dos fundamentos da ordem econômica, porém não se pode desconsiderar o preceito da justiça social e os princípios.

\title{
4 A LEI 13.874 E OS IMPACTOS NO DIREITO EMPRESARIAL
}

A lei da liberdade econômica trouxe mudanças significativas ao Direito Empresarial, uma vez que procurou proporcionar a desburocratização e a simplificação de processos para as sociedades empresárias e empreendedores. Para tal, observa-se as alterações no artigo 
1.052 do Código Civil, que dispõe sobre a Sociedade Limitada, e a inclusão do §7 no artigo 980-A, que versa sobre a desconsideração da pessoa jurídica da EIRELI.

\subsection{A "Sociedade Unipessoal" e a EIRELI}

Com a mudança no artigo 1.052 do Código Civil Brasileiro, estabeleceu-se que " $a$ sociedade limitada pode ser constituída por uma ou mais pessoas, hipótese em que se aplicarão ao documento de constituição do sócio único, no que couber, as disposições sobre o contrato social."

Há algum tempo, foi buscado no universo Empresarial,um instituto jurídico que permitisse o exercício da atividade empresária com limitação da responsabilidade, por sujeito único. Tal necessidade surgiu devido a inscrição da pessoa natural como empresário individual, perante o órgão de registro do comércio, acarretar na responsabilidade ilimitada do mesmo nas obrigações contraídas, sujeitando o patrimônio pessoal deste à ação de seus credores. Em atendimento a essa necessidade foi criada a Lei 12.441, de 11 de julho de 2011, que inseriu a "Empresa Individual de Responsabilidade Limitada - EIRELI" na realidade jurídica brasileira, por meio da inclusão do inciso VI ao artigo 44 do Código Civil e da introdução, no livro II da parte especial, dedicado ao tratamento do Direito de Empresa, do artigo 980-A e seus cinco parágrafos.

A EIRELE regularizou as sociedadespro forma que se caracterizavam por aquelas nas quais um dos sócios normalmente detém a quase totalidade das quotas representativas do capital social (normalmente com o equivalente a 99\%) e o outro sócio - em vários casos pertencente ao ciclo familiar, alheio ao desenvolvimento e ao próprio cotidiano da sociedade empresária -como sócio titular de parcela mínima do capital social (em regra 1\%). A mesma conquistou espaço significativo no cenário econômico e empresarial brasileiro, no entanto, deparou-se com obstáculos jurídicos como o fato da mesma conter uma limitação para sua criação no qual o capital social da mesma não poderá ser inferior a 100 (cem) vezes o maior salário-mínimo vigente no País.

A Sociedade Unipessoal, introduzida pela lei 13.874, surgiu no pretexto de expandir as possibilidades do sócio único restringidas pela EIRELE, no qual prevê no artigo 1.052, a responsabilidade restrita do sócio ao valor de suas quotas e aplicação ao seu documento de constituição as disposições sobre o contrato social, no que couber. Em síntese, esta nova possibilidade de empresa oportunizou um novo regime jurídico de apenas um sócio, que é detentor da totalidade de quotas, com responsabilidade atrelada diretamente ao valor do capital por ele integralizado. 
Nesse sentido, observado tais similaridades, observa-se que ao invés de se introduzir a nova figura jurídica das "sociedades limitadas unipessoais", bastariam ajustes no tratamento jurídico da EIRELI, até mesmo a não aderir o termo sociedade a uma empresa de um único sócio. A EIRELE possui a mesma aptidão jurídica para desempenhar-se em papel análogo às sociedades unipessoais em outros sistemas jurídicos. Tais modificações, consistiriam, essencialmente, em adulterar a redação do caput do art. 980-A para acabar com a exigência do “capital mínimo" de 100 (cem) salários mínimos, autorizar a constituição de EIRELE por pessoa jurídica e a alteração da redação do $\S 5^{\circ}$, autorizando a constituição de EIRELI nãoempresária.

Em síntese, apesar das reconhecidas divergências jurídicas que envolvem a EIRELI, tais ajustes contribuiriam para reduzir os impedimentos atualmente existentes e impulsionar a utilização a figura da mesma, em assumir com protagonismo, as funções desempenhadas pelas "sociedades unipessoais" presentes em realidades estrangeiras.

Ademais, para prosperidade da "sociedade unipessoal" no sistema jurídico é fundamental que haja a alteração na regra do artigo 981 do Código Civil, que determina: "Celebram contrato de sociedade as pessoas que reciprocamente se obrigam a contribuir, com bens ou serviços, para o exercício de atividade econômica e a partilha, entre si, dos resultados". Assim, evita-se situação de antinomia entre as regras do artigo 981 - que regula as sociedades em geral - e do artigo 1.052, que versa sobre as sociedades unipessoais, em especial.

\subsection{A Desconsideração da Personalidade Jurídica na EIRELI}

Os principais direitos advindos da personalidade jurídica é a autonomia patrimonial e obrigacional, que não se confunde com a dos seus titulares. Dessa forma, a sociedade Unipessoal com autonomia patrimonial responde pelas obrigações que contrair, assim como a EIRELI - Empresa Individual de Responsabilidade Limitada. Em outras palavras, os bens dos sócios não respondem pelas obrigações da EIRELI ou da sociedade.

A personalização se dá com a averbação no órgão de registro das empresas mercantis. Sendo registrada, a pessoa jurídica passa a ser sujeito de direitos e obrigações, com legitimidade processual ativa e passiva, podendo ser responsabilizada por dano na esfera civil e penal. No entanto, em determinados casos, é possível o afastamento da personalidade jurídica de uma sociedade. São casos de desconsideração da pessoa jurídica quando a sociedade é utilizada como instrumento para a fraude, abuso de direito ou ilicitudes. 
No entanto, analisando o texto da lei 13.874 , inserida no parágrafo sétimo do artigo 980-A, que versa "somente o patrimônio social da empresa responderá pelas dívidas da empresa individual de responsabilidade limitada, hipótese em que não se confundirá, em qualquer situação, com o patrimônio do titular que a constitui, ressalvados os casos de fraude", nota-se que o $\$ 7^{\circ}$ cria regra de exceção aplicável apenas às EIRELIs, afastando, ao que parece, os requisitos gerais da desconsideração da personalidade jurídica previstos no artigo 50, no intuito de restringir as hipóteses de desconsideração da personalidade jurídica da EIRELI "aos casos de fraudes". Dessa forma, observa-se um tratamento jurídico diferenciado à referida espécie de pessoa jurídica.

Observado o artigo 50 Código Civil, o mesmo, atesta que será desconsiderada a pessoa jurídica quando for comprovado o desvio de finalidade ou pela confusão patrimonial. Em outras palavras, para se afastar a autonomia patrimonial da pessoa jurídica e estendê-la para o patrimônio dos seus sócios ou administradores é necessário estar figurada a confusão patrimonial (que consiste na confusão do patrimônio da pessoa jurídica com o de seu integrante) ou o desvio de finalidade (que é quando o seu integrante utiliza da pessoa jurídica para uma finalidade distinta daquela para a qual ela foi criada). Nesse sentido, observa um claro contraste à desconsideração da personalidade jurídica incluída no artigo 980-A, que se limita aos casos de fraudes.

Assim, é oportuno relembrar a justificativa de veto ao $\$ 4^{\circ}$ do texto originário. Afirmouse que:

\footnotetext{
Não obstante o mérito da proposta, o dispositivo traz a e xpressão 'em qualquer situação', que pode gerar divergências quanto à aplicação das hipóteses gerais de desconsideração da personalidade jurídica, previstas no art. 50 do Código Civil. Assim, e por força do $\S 6^{\circ}$ do projeto de lei, aplicar-se-á à EIRELI as regras da sociedade limitada, inclusive quanto à separação do patrimônio.
}

Portanto, entende-se uma contradição ao texto redigido pelo legislador que trouxe uma hipótese excepcional de desconsideração da personalidade jurídica a EIRELI, que diverge, inclusive, com as alterações promovidas pelo mesmo na MP 881/19, artigo 50 do Código Civil.

\section{CONSIDERAÇÕES FINAIS}

Ao analisarmos a MP 881/19 que originou a Lei 13.874, surpreende o fato de uma matéria com tamanha relevância ser tratada como medida provisória sem os pressupostos constitucionais. A ideia de tratar o tema com urgência levou a inobservância de pressupostos constitucionais que regem todo o ordenamento jurídico. Ao interpretar o texto da Lei 13.874, 
observa-se que o princípio da livre iniciativa supra outros princípios constitucionais como os princípios da proteção da dignidade humana, da valorização social do trabalho além da função social da propriedade e proteção ao meio ambiente.

No tocante à liberdade econômica é importante ressaltar que a Constituição Federal trata a livre iniciativa como uma premissa do modelo de economia de mercado. Ao promoverem a liberdade econômica, não foi observada a responsabilidade do Estado de manter a segurança jurídica, ou seja, a estabilidade no ambiente institucional - fato que também é de extrema relevância para o bom funcionamento do mercado.

Dessa forma, embora se reconheça o intuito de promover o desenvolvimento da atividade econômica no cenário brasileiro, considera-se que as alterações decorrentes da MP 881/19, no tocante à parte de "Direito de Empresa" do Código Civil, demandam maiores discussões, já que o instituto jurídico da EIRELI, presente na legislação brasileira, atende as demandas propostas na criação das sociedades unipessoais. Com as medidas convertidas em lei pelo Congresso Nacional, é possível observar situações contraditórias e que podem ser lesivas aos legítimos interesses sociais e econômicos que circulam no ambiente empresarial brasileiro.

Ademais, é necessária uma ampliação quanto à fraude mencionada como caso exclusivo pelo parágrafo sétimo, para que conste também a possibilidade de desconsideração da sua personalidade jurídica nas outras hipóteses previstas pela legislação.

Em linhas finais, observa-se a crítica feita por Mário Luiz Delgado (2019), ao afirmar que: "a inclusão desse parágrafo era desnecessária, eis que o $§ 6^{\circ}$ já dispõe sobre a aplicação à EIRELI das regras da sociedade limitada, inclusive quanto à separação do patrimônio". Delgado também sustenta, a aplicação do art. 50 à EIRELI : "de qualquer forma, a absoluta separação patrimonial entre a empresa e o seu titular não afasta as hipóteses gerais de desconsideração da personalidade jurídica, previstas no art. 50 do Código Civil”. Deste modo, do ponto de vista prático, observa-se os riscos efetivos que essa nova interpretação da desconsideração personalidade jurídica trouxe a jurisprudência, uma vez que esta última estará lidando com duas regras contraditórias.

\section{REFERÊNCIAS}

BRASIL, Lei n ${ }^{\circ} 13.874$, de 20 de setembro de 2019. Diário Oficial da União. Disponível em: http://www.planalto.gov.br/ccivil_03/_ato2019-2022/2019/lei/L13874.htm. Acesso em 20 de Ago. 2019.

BRASIL, Constituição da República Federativa do Brasil de 1988. Nós representantes do 
povo brasileiro, reunidos em Assembleia Nacional Constituinte para instituir um estado democrático, destinado a assegurar o exercício dos direitos sociais e individuais Diário Oficial da União, Brasília, em 5 out. 1988. Disponível em:

http://www.planalto.gov.br/ccivil_03/constituicao/constituicaocompilado.htm. Acesso em: 20 Ago. 2019.

BOBBIO, Norberto. Liberalismo e democracia. $1^{\circ}$ edição Editora Brasiliense, 1988; pg 17 e 18.

COELHO, Fábio Ulhôa. Curso de Direito Comercial - Sociedades. $17^{a}$ edição. São Paulo: Saraiva, 2013, p. 46/47

DELGADO, Mario Luiz. Código civil comentado: doutrina e jurisprudência. Rio de Janeiro: Forense, 2019. p. 668

FIUZA,César. Direito Civil Curso Completo. $17^{\circ}$ edição Editora del Rey. 2014; pg 180.

FLORES, Itacir Amauri. Regime jurídico e espécies de sociedade unipessoal no Brasil. JUS.COM.BR, outubro de 2015.Disponível em: https://jus.com.br/artigos/43548/regimejuridico-e-especies-de-sociedade-unipessoal-no-brasil. Acesso em 08 Ago. 2019

GONÇALVES NETO, Alfredo de Assis. Direito de Empresa (Comentários aos arts. 966 a 1.195 do CC). $4^{\text {a }}$ edição. São Paulo: RT, 2012.p. 123

LACERDA, Maurício Andere Von Bruck. Primeiras reflexões sobre os impactos da MP 881/19 em relação às regras do "Livro II - Do Direito de Empresa" da parte especial do Código Civil. Migalhas, São Paulo, 08 de maio de 2019. Disponível em: https://www.migalhas.com.br/dePeso/16,MI301806,21048Primeiras+reflexoes+sobre+os+im pactos+da+MP+88119+em+relacao+as. Acesso em 08 Ago. 2019.

LÔBO, Paulo. Inconstitucionalidades da MP da liberdade econômica e do direito civil. Revista Consultor Jurídico, São Paulo, 06 de junho de 2019. Disponível em: https://www.conjur.com.br/2019-jun-06/paulo-lobo-inconstitucionalidades-mp881-direitocivil. Acesso em 08 Ago. 2019.

ROMANO, Rogério Tadeu. Medida provisória 881: uma aberração Jurídica. JUS.COM.BR, julho de 2019. Disponível em: https://jus.com.br/artigos/75247/medidaprovisoria-881-uma-aberracao-juridica. Acesso em 08 Ago. 2019.

SANCHEZ, Alessandro. MP 881 e a Liberdade Econômica- Os Reflexos na EIRELI e Sociedade Limitada Unipessoal. Estratégia Concursos, 04 de maio de 2019. Disponível em: https://www.estrategiaconcursos.com.br/blog/mp-da-liberdade-economica-os-reflexos-naeireli-e-a-sociedade-limitada-unipessoal/. Acesso em 19 Set. 2019 